\title{
Expansion of $\mathrm{T}$ cells targeting multiple antigens of cytomegalovirus, Epstein-Barr virus and adenovirus to provide broad antiviral specificity after stem cell transplantation
}

\author{
Patrick J. Hanley ${ }^{1,2}$, Donald R. Shaffer ${ }^{3}$, Conrad R. Y. Cruz ${ }^{4}$, Stephanie $\mathrm{Ku}^{4}$, Benjamin \\ Tzou $^{4}$, Hao Liu ${ }^{5}$, Gail Demmler-Harrison ${ }^{3}$, Helen E. Heslop ${ }^{4}$, Clio M. Rooney ${ }^{3}$, Stephen \\ Gottschalk $^{4}$, and Catherine M. Bollard ${ }^{3}$ \\ ${ }^{1}$ Texas Children's Hospital, Cell and Gene Therapy, Houston, Texas, USA \\ ${ }^{2}$ Baylor College of Medicine, Immunology, Houston, Texas, USA \\ ${ }^{3}$ Baylor College of Medicine, Pediatrics, Houston, Texas, USA \\ ${ }^{4}$ Baylor College of Medicine, Center for Cell and Gene Therapy, Houston, Texas, USA \\ ${ }^{5}$ Baylor College of Medicine, Medicine, Houston, Texas, USA
}

\begin{abstract}
Background aims-Hematopoietic stem cell transplant (HSCT) is the treatment of choice for a proportion of patients with hematologic malignancies as well as for non-malignant diseases. However, viral infections, particularly Epstein-Barr virus (EBV), cytomegalovirus (CMV) and adenovirus (Ad), remain problematic after transplant despite the use of antiviral drugs. We have shown that cytotoxic T lymphocytes (CTL) generated against CMV-pp65, EBV and Ad antigens in a single culture are capable of controlling infections with all three viruses after HSCT. Although pp65-specific CTL have proved efficacious for the control of CMV infection, several reports highlight the importance of targeting additional CMV antigens.
\end{abstract}

Methods-To expand multivirus-specific T cells with activity against both CMV-pp65 and CMV-IE-1, peripheral blood mononuclear cells (PBMC) were transduced with the adenoviral vector (Ad5f35-IE-1-I-pp65). After 9-12 days the CTL were restimulated with autologous EBVtransformed B cells transduced with the same Ad vector.

Results-After 18 days in culture nine CTL lines expanded from less than $1.5 \times 10^{7}$ PBMC to a mean of $6.1 \times 10^{7} \mathrm{~T}$ cells that recognized CMV antigens pp65 [median 273 spot-forming cells (SFC), range 47-995] and IE-1 (median 154 SFC, range 11-505), the Ad antigens hexon (median 153 SFC, range 26-465) and penton (median 37 SFC, range 1-353), as well as EBV lymphoblastoid cell lines (median $55 \mathrm{SFC}$, range 9-301). Importantly, the T cells recognized at least two antigens per virus and lysed virus peptide-pulsed targets.

Conclusions-CTL that target at least two antigens each of CMV, EBV and Ad should have clinical benefit with broad coverage of all three viruses and enhanced control of CMV infections compared with current protocols.

\section{(C) 2011 Informa Healthcare}

Correspondence: Dr Catherine M. Bollard, Baylor College of Medicine, Pediatrics, Medicine and Immunology, 6621 Fannin Street, MC2-2230, Houston, TX 77030, USA.cmbollar@txccc.org.

Declaration of interest: The authors report no conflicts of interest. The authors alone are responsible for the content and writing of the paper. 


\section{Keywords}

adenovirus; adoptive immunotherapy; antiviral immunity; cytotoxic T lymphocytes; cytomegalovirus; Epstein-Barr virus; stem cell transplant

\section{Introduction}

Hematopoietic stem cell transplantation (HSCT) has improved survival for many individuals with hematologic malignancies. Unfortunately, the immune suppression necessary to prevent graft-versus-host disease in those without HLA-matched related donors leaves patients susceptible to viral infections, most notably Epstein-Barr virus (EBV), cytomegalovirus (CMV) and adenovirus (Ad) (1-3). Although antiviral drugs can be effective for CMV, they are associated with the development of drug-resistance and significant toxicity $(4,5)$, and no antiviral drug can control EBV-associated lymphoproliferative disorder because it is associated with the latent phase of the virus, with the exception of rituximab (6). Cidofovir is the standard treatment for Ad, but must be given intravenously, is associated with significant toxicity, and does not confer long-term protection (7).

The adoptive transfer of cytotoxic T lymphocytes (CTL) as treatment or prophylaxis of viral infection after transplantation has shown clinical efficacy without significant toxicity (8-10). To avoid the use of live viruses, some groups have used CMV-specific CTL targeting the immunodominant 65-KDa tegument phosphoprotein pp65 (11-13). While these trials were successful, it has been suggested that pp65-specific CTL may not always be protective in vivo (14). This may be because of strain differences or mutations that alter important CTL epitopes within pp65, or it may reflect differences in antigens presented during different phases of the CMV life cycle. The tegument protein, pp65, is carried into the newly infected cell as a part of the virion, then processed and presented shortly after viral infection without a requirement for viral gene expression and before the expression of viral proteins that inhibit the immune response (15). Thus pp65-specific T cells may eliminate newly infected cells before they can replicate infectious virus and therefore limit virus spread. However, pp65-specific T cells cannot target cells that reactivate virus from latency when the first protein to be presented is the immediate early protein (IE) (12). In contrast, CMV IEspecific T cells may not be able to control newly infected cells because their own presentation to the immune response is curtailed by virion proteins (16). Therefore complete control of CMV may require the presence of both IE- and pp65-specific T cells (17). Interestingly, IE-1- but not pp65-specific $\mathrm{T}$ cells were associated with protection against CMV disease in a solid organ transplant setting (14).

In healthy CMV-seropositive individuals, IE-1-specific T cells are more abundant than pp65-specific T cells (18). Moreover, after vaccination with the CMV Towne strain, responses to IE- 1 are stronger and more sustained than responses to pp65, indicating that IE-1 T cells contribute to CMV-specific immunity (19).

We have shown that EBV-, Ad- and CMV-pp65-specific CTL (multivirus CTL) can be expanded for clinical use from a single culture and exhibit antiviral activity in vivo $(8,20,21)$. While all patients have been protected against EBV and Ad, three patients developed CMV reactivation after CTL infusion, suggesting that targeting only pp65 may be suboptimal (unpublished data). Thus, we sought to develop a good manufacturing practice (GMP)-compliant strategy whereby we could generate T cells against two CMV antigens without sacrificing the breadth of specificity to EBV and Ad. 


\section{Methods}

\section{Generation of recombinant Ad}

Recombinant Ad5f35-IE-1-I-pp65 was generated as described elsewhere (22). A codonoptimized IE-1 fused to an internal ribosomal entry site (IRES) with NheI and SanDI restriction sites was synthesized by Blue Heron Biotechnology (Blue Heron Biotechnology, Bothell, WA, USA) and inserted inframe into pShuttle-pp65. IE-1 and pp65 protein expression was confirmed by fluorescence-activated cell sorter (FACS) analysis of pShuttleIE-1-I-pp65-transfected HEK 293T cells. From pShuttle-IE-1-I-pp65 the expression cassette, containing the CMV promoter, IE-1-I-pp65 and the BGH poly A, was cloned into the E1/E3-deleted adenoviral backbone vector pAd5F35 using pI-SceI and I-CeuI sites. The resultant plasmid was sequenced to confirm IE-1-I-pp65 (SEQwright, Houston, TX, USA). A recombinant Ad was generated as described in the literature at the Gene Vector Laboratory, Baylor College of Medicine (Houston, TX, USA). A plaque positive for IE-1-Ipp65, as judged by polymerase chain reaction (PCR), was expanded, purified and titered by standard procedures.

\section{Generation of multivirus-specific CTL cultures}

Virus-specific CTL were generated from healthy human donors who had consented to a protocol approved by the Institutional Review Board of the Baylor College of Medicine. The donors were typed by the HLA laboratory of The Methodist Hospital, (Houston, TX, USA) and were selected based on the heterogeneity of their HLA types (Table I).

\section{Generation and transduction of EBV-transformed B-cell lines from peripheral blood mononuclear cells}

As the source of EBV antigens, $5 \times 10^{6}$ peripheral blood mononuclear cells (PBMC) were infected with concentrated supernatants from a B95-8 working cell bank, as described previously (23), and used for the establishment of an EBV-transformed lymphoblastoid cell line (LCL). Two days before CTL stimulation, LCL were transduced with Ad5f35-IE-1-Ipp65 at a multiplicity of infection (MOI) of 2500 virus particles (v.p.) for $90 \mathrm{~min}$ at $37^{\circ} \mathrm{C}$. The cells were then resuspended at $5 \times 10^{5}$ cells $/ \mathrm{mL}$ of complete media [RPMI (Hyclone, Rockford, IL, USA) plus fetal bovine serum (FBS) and GlutaMAX] and transferred to a 24well plate at $2 \mathrm{~mL} /$ well and cultured for 2 days before use as stimulator cells.

\section{Generation of multivirus-specific cultures derived from PBMC}

PBMC were isolated and resuspended at $1 \times 10^{6}$ cells $/ \mathrm{mL}$ in a 24-well plate in X-vivo15 serum-free media (Lonza Bioscience, Basel, Switzerland) with $2 \mathrm{~m}$ м -glutamine (GlutaMAX; Invitrogen, Carlsbad, CA, USA) overnight to activate monocytes (24). The next day the adherent and non-adherent cells were harvested, transduced using the Ad5f35IE-1-I-pp65 vector at an MOI of 2500 v.p., and incubated for $1 \mathrm{~h}$ at $37^{\circ} \mathrm{C}$. After incubation the cells were washed and resuspended at $2 \times 10^{6}$ cells/well in a 24-well plate in CTL media [45\% RPMI (Hyclone), 45\% Clicks (Irvine Scientific, Santa Ana, CA, USA) plus 10\% human serum and GlutaMAX]. Ten days later, T cells were stimulated with autologous LCL transduced with the same Ad5f35-IE-1-I-pp65 vector. T cells were also fed twice weekly with 50-100 U/mL IL-2 starting on day 11 and continuing to day 13.

\section{Enzyme-linked immunospot assay}

Enzyme-linked immunospot (ELISPOT) analysis was used to determine the frequency and function of T cells in the CTL lines secreting interferon (IFN)- $\gamma$ when stimulated with pepmixes $^{\mathrm{TM}}$ (JPT Peptide Technologies, Berlin, Germany) for CMV-pp65, Ad-hexon, Adpenton CMV-IE-1 and EBV (BZLF-1, EBNA3a,b,c and LMP1,2), as described previously 
(8). Spot-forming cells (SFC) were enumerated by Zellnet Consulting (New York, NY, USA) and compared with input cell numbers to obtain the frequency of virus-reactive $T$ cells.

\section{Immunophenotyping, multimer analysis and intracellular cytokine staining}

CTL lines were analyzed with monoclonal antibodies to CD3, CD4, CD8, CD56, CD16, CD45RA and CD62L (Becton Dickinson, Franklin Lakes, NJ, USA) To detect CMV-pp65and CMV-IE-1-specific T cells in the CTL lines, we used the soluble CMV-pp65 pentamers HLA-A*0201-NLVPMVATV, HLA-A*24-QYDPVAALF, HLA-B7-TPRVTGG-GAM, HLA-A*01-YSEHPTFTSQY, CMV-IE-1 HLA-B*08-QIKVRVDMV, HLA-A*02VLEETS-VML and HLA-A*02-VLAELVKQI, prepared by Proimmune Inc. (Springfield, VA, USA) as described previously. Cells were stained with the pentamer at $4^{\circ} \mathrm{C}$ in the dark for $20 \mathrm{~min}$, washed, and then stained with a phycoerythrin (PE)- or Allophycocyanin (APC)labeled streptavidin fluorophore. To define the CD4- and CD8- restricted CMV- and Adspecific activity, we employed intracellular cytokine staining. Briefly, we pulsed T cells with CMV or Ad pepmixes overnight in the presence of anti-CD49d and anti-CD28 antibodies (Becton Dickinson) for co-stimulation and Brefeldin A (Becton Dickinson) to retain the cytokine within the cell. The next day, cells were fixed with $4 \%$ paraformaldehyde (Becton Dickinson), permeabilized with 1\% Saponin (Sigma, St Louis, MO, USA), and stained for IFN- $\gamma$ and surface markers (Becton Dickinson). Samples were acquired on a FACScan flow cytometer (Becton Dickinson) and the data analyzed using CellQuest software (Becton Dickinson). To verify the expression of IE-1 and pp65 after vector transduction by intracellular staining, 293T cells and LCL were transduced with the Ad5f35IE-1-I-pp65 vector. The next day they were fixed and permeabilized as described above. A mouse monoclonal antibody to CMV-pp65 (Santa Cruz Biotechnology Inc., Santa Cruz, CA, USA) and mouse monoclonal antibody to CMV-IE-1 (clone CH160; Abcam, Cambridge, MA, USA) were used for primary staining, and goat antimouse PE (GAM-PE; Becton Dickinson) was used for secondary staining. Isotype controls were 293T cells incubated with GAM-PE alone.

\section{Peptide pools to evaluate the breadth of the virus-specific response}

Panels of 20-mer peptides (overlapping by 15 amino acids) covering the entire amino acid sequence of CMV-pp65 and CMV-IE-1 from the AD169 strain and Ad hexon from serotype 5 were synthesized (Proimmune, Oxford, UK) (25). For CMV-pp65, 22 peptide pools comprising 2-12 20-mer peptides were prepared, so that each 20-mer peptide was represented in two pools (26). For CMV-IE-1, 20 peptide pools composed of either 8 or 12 20 -mer peptides were prepared similar to CMV-pp65. For Ad-hexon, 11 peptide pools contained 17 or 18 peptides, so that each 20-mer peptide was represented in one pool, as described previously (26). These CMV-pp65, CMV-IE-1 and Ad-hexon peptide libraries were designed to identify HLA class I- and class II-restricted epitopes (27).

\section{Cytotoxicity assay}

CTL were tested for specific cytotoxicity against autologous LCL (22) and autologous LCL pulsed with CMV-IE-1, CMV-pp65, Ad-hexon and Ad-penton pepmixes. ${ }^{51} \mathrm{Cr}$-labeled target cells were mixed with effector cells at doubling dilutions to produce the effector:target (E:T) ratios specified. Target cells incubated in complete medium or 5\% Triton X-100 (Sigma) were used to determine spontaneous and maximal ${ }^{51} \mathrm{Cr}$ release, respectively. After 4 $\mathrm{h}$, supernatants were collected and radioactivity was measured on a gamma counter. The mean percentage of specific lysis of triplicate wells was calculated as $100 \times$ (experimental release - spontaneous release)/(maximal release - spontaneous release). The ability of effector cells to lyse CMV-infected targets was assessed by using HLA-A*0201 + fibroblasts infected with the AD169 laboratory strain of CMV. 


\section{Statistical analysis}

The Student's $t$-test was used to test for the difference between groups, assuming equal variance. Mean values \pm SD are given unless otherwise stated.

\section{Results}

\section{Ex vivo-generated multivirus-specific $T$ cells expand to clinically relevant numbers and are $\mathrm{CD4}^{+}$and $\mathrm{CD}^{+}{ }^{+}$with an effector memory phenotype}

As shown in Figure 1a,b, both IE-1 and pp65 proteins were expressed from the Ad5f35IE-1-I-pp65 vector after transfection with the pShut-tle-IE-1-I-pp65 plasmid (Figure 1a) and transduction with Ad5f35-IE-1-I-pp65 vector, as evaluated by intracellular staining and Western blot analysis (Figure 1b). After an initial stimulation of $0.1-1.4 \times 10^{7} \mathrm{PBMC}$ with activated monocytes transduced with Ad5f35-IE-1-I-pp65 and a second stimulation with autologous LCL transduced with the same vector, the mean T-cell number in nine CTL lines was $6.1 \times 10^{7}$ with a range of $1.0 \times 10^{7}-1.2 \times 10^{8}$ (Figure 1c) by days $16-19$ of culture. Based on our previous studies, the targeted cell dose of CTL was $1 \times 10^{7} / \mathrm{m}^{2}(8)$, suggesting that by days 16-19 we were able to expand a clinically relevant number of CTL. Phenotypic analysis performed after day 19 of culture revealed that the expanded $\mathrm{T}$ cells consisted predominantly of $\mathrm{CD}^{+} \mathrm{T}$ cells, with minimal expansion of natural killer (NK) cells (CD16/ CD56) (Figure 1d). CMV-specific cells, identified by pentamer, consisted of central memory and effector memory $\mathrm{T}$ cells (Figure 1e).

\section{Multivirus-specific CTL recognize multiple antigens within CMV, EBV and Ad}

To determine the specificity and function of the expanded T cells, we measured IFN- $\gamma$ release in response to antigenic stimulation in ELISPOT assays, intracellular cytokine staining, epitope specificity by ELISPOT and pentamer staining, and cytotoxic function in chromium release assays. T cells generated with the Ad5f35-IE-1-I-pp65 vector secreted IFN- $\gamma$ in response to the CMV antigens pp65 (median 273 SFC, range 47-995) and IE-1 (median 154 SFC, range 11-505), as well as to the Ad antigens hexon (median 153 SFC, range 26-465) and penton (median $37 \mathrm{SFC}$, range 1-353) and to EBV LCL (median 55 SFC, range 9-301) (Figure 2a and Table II). Responses to all four antigens tested and to the EBV-LCL were significantly above negative controls (median 7 SFC, range $0-48 ; P<$ 0.00001 ). Taken together, these data suggested that we were able to generate reliably T-cell responses specific for CMV-pp65, IE-1, Ad hexon and penton, and EBV antigens expressed by LCL. More importantly, the donors tested responded to at least two antigens from each virus when tested by IFN- $\gamma$ ELISPOT or intracellular IFN- $\gamma$ staining (Figure $2 \mathrm{a}-\mathrm{c}$ ).

Given the importance of both $\mathrm{CD} 4^{+}$and $\mathrm{CD} 8^{+} \mathrm{T}$ cells in controlling viral infection, we wanted to analyze the subset of $\mathrm{T}$ cells $\left(\mathrm{CD}^{+}{ }^{+}\right.$or $\left.\mathrm{CD} 8^{+}\right)$secreting cytokines after stimulation with viral antigens. We showed that the responding $\mathrm{T}$ cells specific for the CMV antigens IE-1 and pp65 were predominantly CD8 ${ }^{+}$with a small $\mathrm{CD}^{+} \mathrm{T}$-cell response (Figure $2 \mathrm{~b}$ ). In contrast, the adenoviral antigens hexon and penton elicited a predominantly $\mathrm{CD}^{+} \mathrm{T}$-cell response, as measured by IFN- $\gamma$. This corroborated previous reports that show mainly CD8 ${ }^{+}$ $\mathrm{T}$-cell responses against pp65 and IE- 1 antigens and $\mathrm{CD} 4^{+} \mathrm{T}$-cell responses against hexon and penton (8).

\section{Multivirus-specific CTL retain a broad epitope specificity}

To determine the breadth of the multivirus-specific T-cell response generated using our novel Ad5f35-IE-1-I-pp65 vector, we used overlapping peptide pools as described previously (26-28). Using IE-1, pp65 and hexon peptide pools, we mapped the epitope responses from multivirus-specific $\mathrm{T}$ cells from nine healthy donors. All s multiple peptides from both IE-1 and pp65, including known HLA-restricted immunodominant peptides, as 
well as peptides and peptide pools representing previously undescribed peptides (Figure 3a$\mathrm{c}$ and Table I). Known epitopes restricted by HLA class I alleles A1, A2, A24, B7 and B8 were also analyzed by pentamer staining. Four HLA-A2 + donors recognized the immunodominant HLA-A2-restricted CMV-pp65 epitope NLVPM-VATV, while two of these donors recognized the HLA-A2-restricted CMV-IE-1-restricted epitopes VLEETSVML and VLAELVKQI (Figure $3 \mathrm{c}$ and Table I). As with CMV-IE- 1 and CMVpp65, T cells specific for Ad hexon also recognized multiple epitopes (Figure 3a,b and Table I).

\section{Multivirus-specific CTL can lyse antigen-pulsed and virus-infected targets}

Cytolytic activity was tested against a panel of ${ }^{51} \mathrm{Cr}$-labeled autologous target cells. While EBV LCL were lysed by a proportion of CTL lines similar to our previous experience (8), reflecting EBV specificity, killing was increased if LCL were pulsed with the pepmixes representing CMV-pp65, CMV-IE-1 and Ad-hexon/penton (Figure 4a,b and Table III). Since antigens and epitopes presented by overlapping peptides may not represent the pattern or frequency of epitopes expressed by cells infected with virus, we infected fibroblasts with CMV AD169 and used them as targets for our CTL (20). As shown in Figure 4c, the multivirus-specific $\mathrm{T}$ cells were capable of lysing CMV-infected targets.

\section{Discussion}

We have shown that after 18 days in culture we can generate $T$ cells that target multiple epitopes from at least two antigens of CMV, EBV and Ad, as determined by peptide pool analysis as well as multimer analysis. Notably, the expansion of $\mathrm{T}$ cells targeting at least two immunodominant antigens (CMV-pp65 and CMV-IE-1) does not limit the breadth of the response to other less immunogenic antigens. Resulting $\mathrm{T}$ cells lyse peptide-pulsed targets for each antigen as well as CMV-AD169-infected fibroblasts.

After hematopoietic stem cell transplant, there is increased risk for viral infection. Anti-viral drugs are available and can be effective, but are costly and associated with unacceptable side-effects (29-31). The adoptive transfer of virus-specific $\mathrm{T}$ cells, however, has proved safe and effective for many viruses, including CMV, EBV and Ad $(8,13,32-36)$. Furthermore, virus-specific T-cell infusions have not been associated with appreciable infusion-related toxicity (37) and gene-marked virus-specific T cells have been detected in patients up to 10 years after transplant, indicating that the transferred $\mathrm{T}$ cells persist and provide long-term protection against viral infection (38).

The effective control of virus infection or reactivation in all patients will probably entail not only targeting multiple viruses as we do here, but also multiple epitopes and even multiple viral antigens, to avoid problems with strain variations, mutations and the patterns of virus gene expression and presentation occurring at different phases of the virus life cycle.

Unfortunately, when $\mathrm{T}$ cells are stimulated with multiple antigens in a single culture, $\mathrm{T}$ cells specific for highly immunodominant antigens, such as CMV-pp65, may out-compete $\mathrm{T}$ cells specific for other less-immunogenic antigens, such as the adenoviral antigen hexon (21). We now show that even the introduction of two immunodominant antigens from CMV does not limit the generation of T cells specific for hexon, penton, pp65, IE-1 and EBV. Within only 3 weeks of culture, we could expand these multivirus-specific T cells to clinically relevant numbers within which subpopulations of $\mathrm{T}$ cells with specificity against multiple antigens and epitopes derived from all three viruses could be detected. Although the addition of IE-1 does not limit the expansion of T cells specific for other antigens, we have observed in the past that the frequency of EBV-specific T cells in the cultures is lower than for CMV or Ad and too low in some cultures for their cytotoxic function to be detected. This is probably because these CTL lines have received two rounds of stimulation with CMV and Ad but 
only a single stimulation with EBV. However, after transfer to patients with EBV-associated disease, even when T-cell function can be detected only by more sensitive IFN- $\gamma$ release assays the $\mathrm{T}$ cells are able to proliferate and control EBV infection.

To test the breadth of the epitope responses we used overlapping peptide pool technologies that allowed us to analyze T-cell responses to three different antigens (CMV-IE-1, CMVpp65 and Ad-hexon) and determined that $\mathrm{T}$ cells can indeed recognize multiple epitopes (or peptide pools) within each protein. Previously, we have expanded CMV, EBV and Adspecific $\mathrm{T}$ cells from naive cord blood $\mathrm{T}$ cells, and have shown that these in vitro-primed virus-specific $\mathrm{T}$ cells recognize only unconventional (non-immunodominant) epitopes of CMV-pp65. In contrast, the expansion of in vivo-primed virus-specific T cells results in an enrichment of T cells that recognize conventional epitopes of CMV-pp65 and CMV-IE-1.

Although the predominant response in most donors is to known immunodominant epitopes such as the HLA-A2-restricted NLVPMVATV peptide (CMV-pp65 pools 2 and 21), other less-dominant responses are also shown in other pools, confi rming the broad epitope specificity (Figure 3a,b and Table I). Moreover, we were able to target multiple antigens from each virus, therefore maximizing the anti-viral T-cell response and minimizing the potential for antigenic escape when used clinically (39).

Cytolytic function is typically attributed to $\mathrm{CD} 8^{+}$cytotoxic $\mathrm{T}$ cells, but we have previously demonstrated the cytolytic function of $\mathrm{CD} 4^{+}$virus-specific $\mathrm{T}$ cells (40), and the importance of $\mathrm{CD}^{+}{ }^{+}$virus-specific $\mathrm{T}$ cells in immune reconstitution and antiviral immunity has recently been highlighted. In a study of renal transplant patients undergoing primary CMV infection, patients with asymptomatic infection had $\mathrm{CD} 4^{+} \mathrm{T}$-cell populations that preceded the $\mathrm{CD} 8^{+}$ population, whereas patients developing CMV disease had a delayed emergence of $\mathrm{CD} 4{ }^{+} \mathrm{T}$ cells (41). Similar results were shown after bone marrow transplant when the adoptive transfer of $\mathrm{CD}^{+} \mathrm{T}$ cells protected patients from CMV disease: their persistence was dependent upon the presence of $\mathrm{CD} 4^{+} \mathrm{T}$ cells $(35,36,42,43)$. Therefore, targeting multiple epitopes and multiple viral antigens, as well as using a combination of $\mathrm{CD}^{+}$and $\mathrm{CD} 8^{+} \mathrm{T}$ cells, is likely to increase the efficacy of the CTL in vivo .

Interestingly, the multivirus-specific T cells generated with the Ad5f35-IE-1-I-pp65 vector have an increased proportion of $\mathrm{CD} 4^{+} \mathrm{T}$ cells compared with $\mathrm{T}$ cells stimulated with the Ad5f35-pp65 vector. In our clinical protocols using virus-specific $\mathrm{T}$ cells, the variation in the frequency of the $\mathrm{CD} 4^{+} \mathrm{T}$-cell population has been similar, ranging from less than $2 \%$ to greater than $98 \%$ of $\mathrm{T}$ cells, with clinical efficacy as a result of both types of lines $(8,38)$. As shown in Figure 1d, e and Figure 2b, the CTL that we generate using this novel vector are indeed a heterogeneous population of effector memory $\left(\mathrm{CD}^{2} 5 \mathrm{RA}^{+} / \mathrm{CD}^{2} 2 \mathrm{~L}^{-}\right.$and $\mathrm{CD} 45 \mathrm{RA}^{-} /$ $\left.\mathrm{CD}^{2} \mathrm{~L}^{-}\right)$and central memory $\left(\mathrm{CD} 45 \mathrm{RA}^{-} / \mathrm{CD} 6 \mathrm{~L}^{+}\right) \mathrm{T}$ cells with both $\mathrm{CD} 4^{+}$and $\mathrm{CD} 8^{+} \mathrm{T}$ cells responding to each viral antigen tested.

In conclusion, we have developed a novel and reliable strategy for the expansion of multivirus-specific $\mathrm{T}$ cells targeting multiple antigens in three viruses including the immunodominant CMV antigens IE-1 and pp65. We have begun to develop a clinical study to test the safety and efficacy of multivirus-specific CTL with an IE-1 and pp65 component.

\section{Acknowledgments}

This work was supported by a grant from the Virginia and LE Simmons Family Foundation, a Specialized Centers for Cell-based Therapy Grant (NIH-NHLBI 1 U54 HL081007) and a Production Assistance for Cellular Therapies grant (N01-HB-37163). 


\section{References}

1. Chakrabarti S, Mackinnon S, Chopra R, Kottaridis PD, Peggs K, O’Gorman P, et al. High incidence of cytomegalovirus infection after nonmyeloablative stem cell transplantation: potential role of Campath-1H in delaying immune reconstitution. Blood. 2002; 99:4357-4363. [PubMed: 12036862]

2. Chakrabarti S, Mautner V, Osman H, Collingham KE, Fegan CD, Klapper PE, et al. Adenovirus infections following allogeneic stem cell transplantation: incidence and outcome in relation to graft manipulation, immunosuppression, and immune recovery. Blood. 2002; 100:1619-1627. [PubMed: 12176880]

3. Tomblyn M, Chiller T, Einsele H, Gress R, Sepkowitz K, Storek J, et al. Guidelines for preventing infectious complications among hematopoietic cell transplantation recipients: a global perspective. Biol Blood Marrow Transplant. 2009; 15:1143-1238. [PubMed: 19747629]

4. Bao L, Dunham K, Stamer M, Mulieri KM, Lucas KG. Expansion of cytomegalovirus pp65 and IE-1 specific cytotoxic T lymphocytes for cytomegalovirus-specific immunotherapy following allogeneic stem cell transplantation. Biol Blood Marrow Transplant. 2008; 14:1156-1162. [PubMed: 18804046]

5. Erice A. Resistance of human cytomegalovirus to antiviral drugs. Clin Microbiol Rev. 1999; 12:286-297. [PubMed: 10194460]

6. Mentzer SJ, Perrine SP, Faller DV. Epstein-Barr virus post-transplant lymphoproliferative disease and virus-specific therapy: pharmacological re-activation of viral target genes with arginine butyrate. Transpl Infect Dis. 2001; 3:177-185. [PubMed: 11493400]

7. Lindemans CA, Leen AM, Boelens JJ. How I treat adenovirus in haematopoietic stem cell transplantation recipients. Blood. 2010; 116:5476-5485. [PubMed: 20837781]

8. Leen AM, Myers GD, Sili U, Huls MH, Weiss H, Leung KS, et al. Monoculture-derived T lymphocytes specific for multiple viruses expand and produce clinically relevant effects in immunocompromised individuals. Nat Med. 2006; 12:1160-1166. [PubMed: 16998485]

9. Riddell SR, Watanabe KS, Goodrich JM, Li CR, Agha ME, Greenberg PD. Restoration of viral immunity in immunode-ficient humans by the adoptive transfer of T cell clones. Science. 1992; 257:238-241. [PubMed: 1352912]

10. O’Reilly RJ, Doubrovina E, Trivedi D, Hasan A, Kollen W, Koehne G. Adoptive transfer of antigen-specific T-cells of donor type for immunotherapy of viral infections following allogeneic hematopoietic cell transplants. Immunol Res. 2007; 38:237-250. [PubMed: 17917029]

11. Laughlin-Taylor E, Pande H, Forman SJ, Tanamachi B, Li CR, Zaia JA, et al. Identification of the major late human cytomegalovirus matrix protein pp65 as a target antigen for $\mathrm{CD}^{+}$virus-specific cytotoxic T lymphocytes. J Med Virol. 1994; 43:103-110. [PubMed: 8083644]

12. Greenberg PD, Reusser P, Goodrich JM, Riddell SR. Development of a treatment regimen for human cytomegalovirus (CMV) infection in bone marrow transplantation recipients by adoptive transfer of donor-derived CMV-specific T cell clones expanded in vitro. Ann NY Acad Sci. 1991; 636:184-195. [PubMed: 1665321]

13. Peggs KS, Verfuerth S, Pizzey A, Khan N, Guiver M, Moss PA, et al. Adoptive cellular therapy for early cytomegalovirus infection after allogeneic stem-cell transplantation with virus-specific T-cell lines. Lancet. 2003; 362:1375-1377. [PubMed: 14585640]

14. Bunde T, Kirchner A, Hoffmeister B, Habedank D, Hetzer R, Cherepnev G, et al. Protection from cytomegalovirus after transplantation is correlated with immediate early 1-specific CD8 T cells. $\mathrm{J}$ Exp Med. 2005; 201:1031-1036. [PubMed: 15795239]

15. Besold K, Frankenberg N, Pepperl-Klindworth S, Kuball J, Theobald M, Hahn G, et al. Processing and MHC class I presentation of human cytomegalovirus pp65-derived peptides persist despite gpUS2-11-mediated immune evasion. J Gen Virol. 2007; 88:1429-1439. [PubMed: 17412970]

16. Gilbert MJ, Riddell SR, Plachter B, Greenberg PD. Cytomegalovirus selectively blocks antigen processing and presentation of its immediate-early gene product. Nature. 1996; 383:720-722. [PubMed: 8878482]

17. Zandvliet ML, van Liempt E, Jedema I, Veltrop-Duits LA, Willemze R, Guchelaar HJ, et al. Coordinated isolation of $\mathrm{CD}^{+}$and $\mathrm{CD} 4^{+} \mathrm{T}$ cells recognizing a broad repertoire of cytomegalovirus 
pp65 and IE1 epitopes for highly specific adoptive immunotherapy. Cytotherapy. 2010; 12:933944. [PubMed: 20078388]

18. Slezak SL, Bettinotti M, Selleri S, Adams S, Marincola FM, Stroncek DF. CMV pp65 and IE-1 T cell epitopes recognized by healthy subjects. J Transl Med. 2007; 5:17. [PubMed: 17391521]

19. Jacobson MA, Sinclair E, Bredt B, Agrillo L, Black D, Epling CL, et al. Antigen-specific T cell responses induced by Towne cytomegalovirus (CMV) vaccine in CMV-seronegative vaccine recipients. J Clin Virol. 2006; 35:332-337. [PubMed: 16387547]

20. Micklethwaite KP, Savoldo B, Hanley PJ, Leen AM, Demmler-Harrison GJ, Cooper LJ, et al. Derivation of human T lymphocytes from cord blood and peripheral blood with antiviral and antileukemic specificity from a single culture as protection against infection and relapse after stem cell transplantation. Blood. 2010; 115:2695-2703. [PubMed: 20110422]

21. Leen AM, Christin A, Myers GD, Liu H, Cruz CR, Hanley PJ, et al. Cytotoxic T lymphocyte therapy with donor $\mathrm{T}$ cells prevents and treats adenovirus and Epstein-Barr virus infections after haploidentical and matched unrelated stem cell transplantation. Blood. 2009; 114:4283-4292. [PubMed: 19700662]

22. Sili U, Huls MH, Davis AR, Gottschalk S, Brenner MK, Hes-lop HE, et al. Large-scale expansion of dendritic cell-primed polyclonal human cytotoxic T-lymphocyte lines using lymphoblastoid cell lines for adoptive immunotherapy. J Immunother. 2003; 26:241-256. [PubMed: 12806278]

23. Rooney CM, Smith CA, Ng CY, Loftin S, Li C, Krance RA, et al. Use of gene-modified virusspecific T lymphocytes to control Epstein-Barr-virus-related lymphoproliferation. Lancet. 1995; 345:9-13. [PubMed: 7799740]

24. Leen A, Ratnayake M, Foster A, Heym K, Ahmed N, Rooney CM, et al. Contact-activated monocytes: efficient antigen presenting cells for the stimulation of antigen-specific T cells. J Immunother. 2007; 30:96-107. [PubMed: 17198088]

25. Kern F, Faulhaber N, Frommel C, Khatamzas E, Prosch S, Schonemann C, et al. Analysis of CD8 $\mathrm{T}$ cell reactivity to cytomegalovirus using protein-spanning pools of overlapping pentadecapeptides. Eur J Immunol. 2000; 30:1676-1682. [PubMed: 10898504]

26. Leen AM, Christin A, Khalil M, Weiss H, Gee AP, Brenner MK, et al. Identification of hexonspecific CD4 and CD8 T-cell epitopes for vaccine and immunotherapy. J Virol. 2008; 82:546-554. [PubMed: 17942545]

27. Chang ST, Ghosh D, Kirschner DE, Linderman JJ. Peptide length-based prediction of peptideMHC class II binding. Bioinformatics. 2006; 22:2761-2767. [PubMed: 17000752]

28. Hanley PJ, Cruz CR, Savoldo B, Leen AM, Stanojevic M, Khalil M, et al. Functionally active virus-specific $\mathrm{T}$ cells that target CMV, adenovirus, and EBV can be expanded from naive T-cell populations in cord blood and will target a range of viral epitopes. Blood. 2009; 114:1958-1967. [PubMed: 19443656]

29. Kumar D, Humar A. Cytomegalovirus prophylaxis: how long is enough? Nat Rev Nephrol. 2010; 6:13-14. [PubMed: 20023684]

30. Salzberger B, Bowden RA, Hackman RC, Davis C, Boeckh M. Neutropenia in allogeneic marrow transplant recipients receiving ganciclovir for prevention of cytomegalovirus disease: risk factors and outcome. Blood. 1997; 90:2502-2508. [PubMed: 9310503]

31. Boeckh M, Gooley TA, Myerson D, Cunningham T, Schoch G, Bowden RA. Cytomegalovirus pp65 antigenemia-guided early treatment with ganciclovir versus ganciclovir at engraftment after allogeneic marrow transplantation: a randomized double-blind study. Blood. 1996; 88:4063-4071. [PubMed: 8916975]

32. Cobbold M, Khan N, Pourgheysari B, Tauro S, McDonald D, Osman H, et al. Adoptive transfer of cytomegalovirusspecific CTL to stem cell transplant patients after selection by HLA-peptide tetramers. J Exp Med. 2005; 202:379-386. [PubMed: 16061727]

33. Gustafsson A, Levitsky V, Zou JZ, Frisan T, Dalianis T, Ljungman P, et al. Epstein-Barr virus (EBV) load in bone marrow transplant recipients at risk to develop posttransplant lymphoproliferative disease: prophylactic infusion of EBV-specific cytotoxic T cells. Blood. 2000; 95:807-814. [PubMed: 10648390]

34. Micklethwaite KP, Clancy L, Sandher U, Hansen AM, Blyth E, Antonenas V, et al. Prophylactic infusion of cytomegalovirusspecific cytotoxic T lymphocytes stimulated with Ad5f35pp65 gene- 
modified dendritic cells after allogeneic hemopoietic stem cell transplantation. Blood. 2008; 112:3974-3981. [PubMed: 18768783]

35. Einsele H, Roosnek E, Rufer N, Sinzger C, Riegler S, Loffler J, et al. Infusion of cytomegalovirus (CMV)-specific T cells for the treatment of CMV infection not responding to antiviral chemotherapy. Blood. 2002; 99:3916-3922. [PubMed: 12010789]

36. Walter EA, Greenberg PD, Gilbert MJ, Finch RJ, Watanabe KS, Thomas ED, et al. Reconstitution of cellular immunity against cytomegalovirus in recipients of allogeneic bone marrow by transfer of T-cell clones from the donor. N Engl J Med. 1995; 333:1038-1044. [PubMed: 7675046]

37. Cruz CR, Hanley PJ, Liu H, Torrano V, Lin YF, Arce JA, et al. Adverse events following infusion of T cells for adoptive immu-notherapy: a 10-year experience. Cytotherapy. 2010; 12:743-749. [PubMed: 20429793]

38. Heslop HE, Slobod KS, Pule MA, Hale GA, Rousseau A, Smith CA, et al. Long-term outcome of EBV-specific T-cell infusions to prevent or treat EBV-related lymphoproliferative disease in transplant recipients. Blood. 2010; 115:925-935. [PubMed: 19880495]

39. Gottschalk S, Ng CY, Perez M, Smith CA, Sample C, Brenner MK, et al. An Epstein-Barr virus deletion mutant associated with fatal lymphoproliferative disease unresponsive to therapy with virus-specific CTLs. Blood. 2001; 97:835-843. [PubMed: 11159505]

40. Savoldo B, Cubbage ML, Durett AG, Goss J, Huls MH, Liu Z, et al. Generation of EBV-specific $\mathrm{CD} 4^{+}$cytotoxic T cells from virus naive individuals. J Immunol. 2002; 168:909-918. [PubMed: 11777989]

41. Waller EC, Day E, Sissons JG, Wills MR. Dynamics of T cell memory in human cytomegalovirus infection. Med Mcrobiol Immunol. 2008; 197:83-96.

42. Foster AE, Bradstock KF, Sili U, Marangolo M, Rooney CM, Gottlieb DJ. A comparison of gene transfer and antigenloaded dendritic cells for the generation of $\mathrm{CD}^{+}$and $\mathrm{CD} 8{ }^{+}$cytomegalovirusspecific T cells in HLA-A2 + and HLA-A2-donors. Biol Blood Marrow Transplant. 2004; 10:761771. [PubMed: 15505607]

43. Matloubian M, Concepcion RJ, Ahmed R. CD4 ${ }^{+} \mathrm{T}$ cells are required to sustain $\mathrm{CD}^{+}$cytotoxic Tcell responses during chronic viral infection. J Virol. 1994; 68:8056-8063. [PubMed: 7966595] 
a

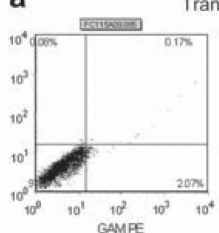

ransfected with pSHUTTLE-IE-1-I-pp65
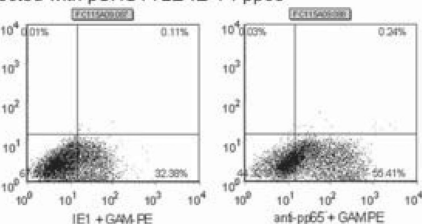

Non-Transfected

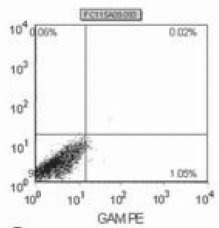

C
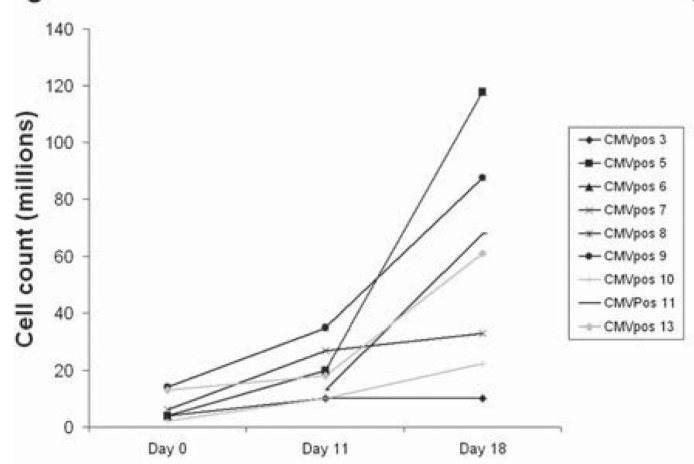

b

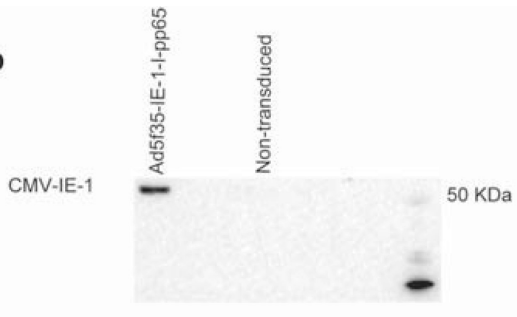

CMV-pp65

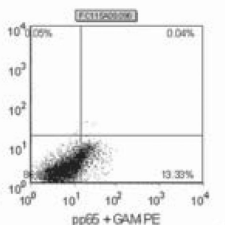

d

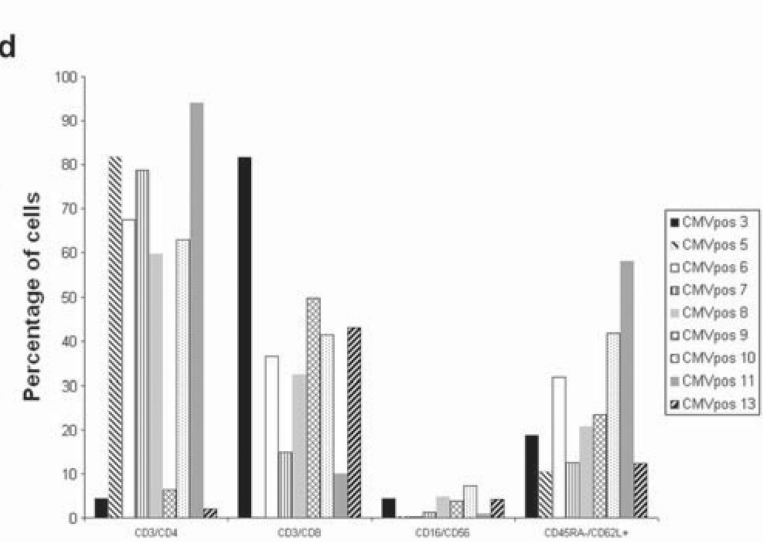

e
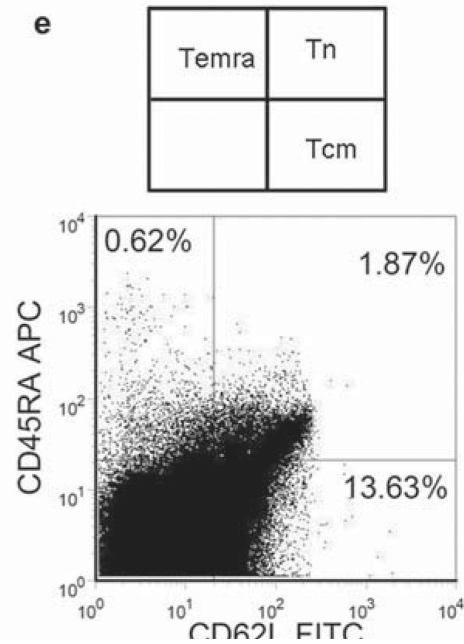

Figure 1.

Expression of CMV-IE-1 and CMV-pp65, T-cell expansion and T-cell phenotype. (a) An intracellular stain of HEK 293T cells transfected with the pSHUTTLE-IE-1-I-pp65 plasmid and stained with anti-IE-1 or anti-pp65. (b) FLY-RD18 cells were transduced with the Ad5f35-IE-1-I-pp65 vector, harvested, and run on a sodium dodecyl sulfate (SDS)polyacrylamide gel electrophoresis (PAGE) gel. Two identical blots were then probed with anti-IE-1 or anti-pp65 antibodies. (c) Expansion of nine CTL lines to day 18. (d) Reactivity of CTL lines to surface markers for CD3, CD4, CD8, CD16, CD56, CD45RA and CD62L. (e) Terminally differentiated effector memory, central memory and naive T-cell populations after gating on $\mathrm{CD}^{+}$and NLVPMVATV $\left(\mathrm{NLV}^{+}\right)$cells. 

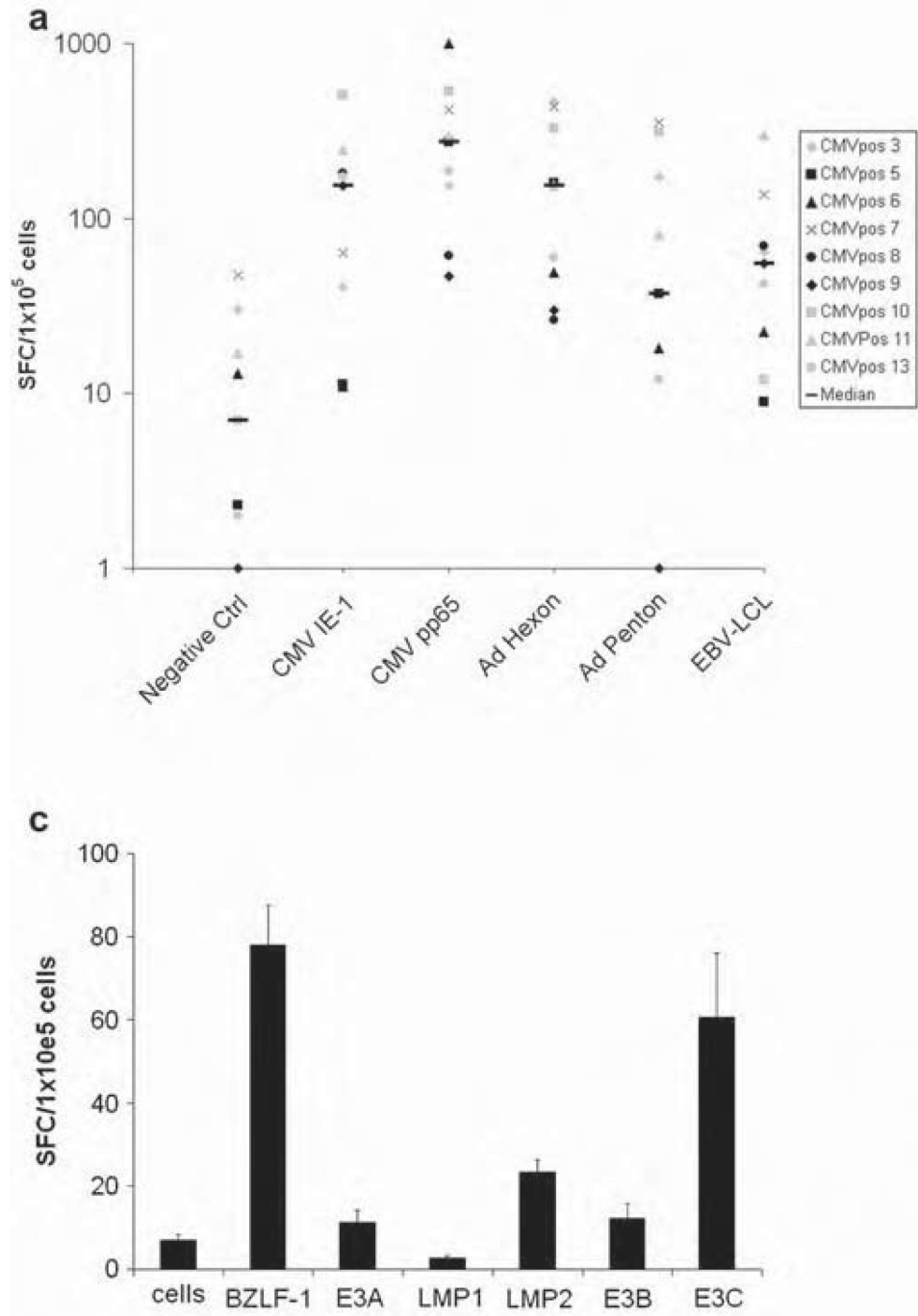

b
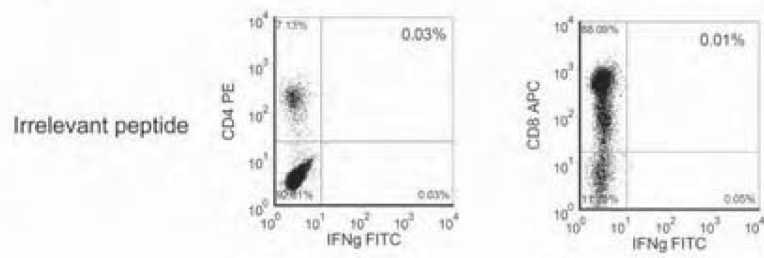

IE1
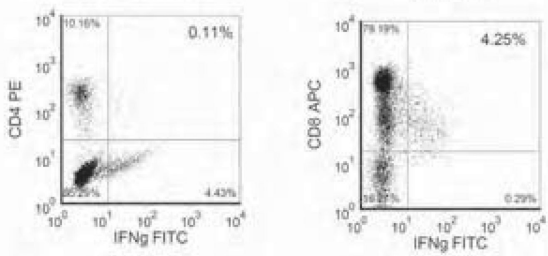

pp65
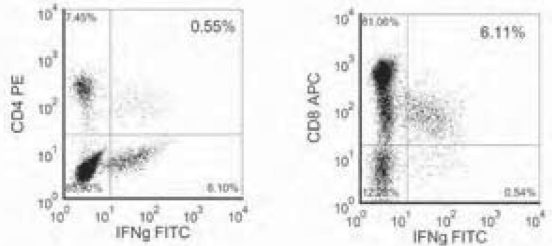

Figure 2.

Virus-specific reactivity of generated $\mathrm{T}$ cells by ELISPOT and intracellular cytokine staining. (a) Virus-specific activity of nine CTL lines as determined by IFN- $\gamma$ ELISPOT assay in response to direct stimulation with CMV-pp65, CMV-IE-1, Ad-hexon, Ad-penton and autologous EBV LCL. For each T-cell line, mean values of duplicate or triplicate experiments are reported and error bars indicate the standard error. (b) Virus-specific activity of resulting $\mathrm{T}$ cells from one representative donor as measured by intracellular cytokine staining of IFN- $\gamma$ after pulsing overnight with CMV-pp65, CMV-IE-1, Ad-hexon or Ad-penton pepmix. (c) A panel of pepmixes against EBV antigens (EBNA-3a, b, and c, as well as LMP1, LMP2 and BZLF-1) was tested against resulting T cells. Data are from one representative T-cell line. For each T-cell line, mean values of duplicate or triplicate experiments are reported and error bars indicate the standard deviation. 
a

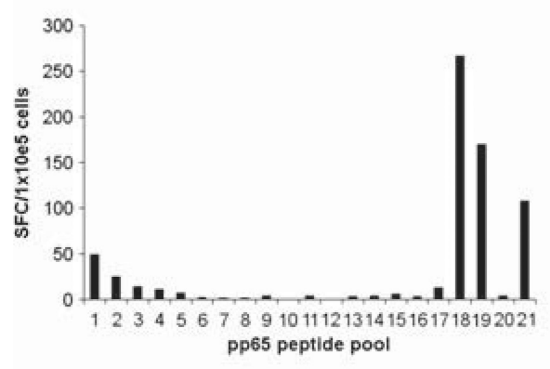

b

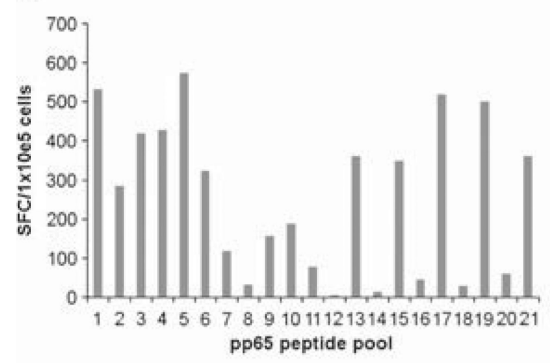

CMVpos 13
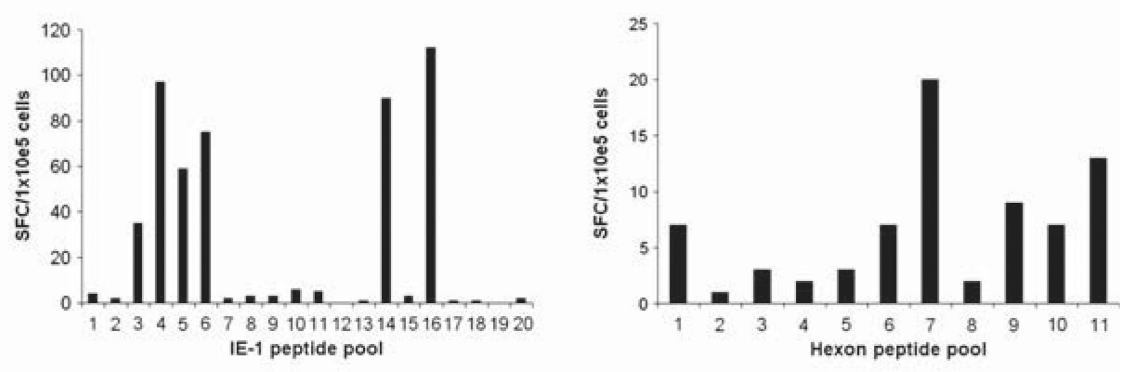

CMVpos 10
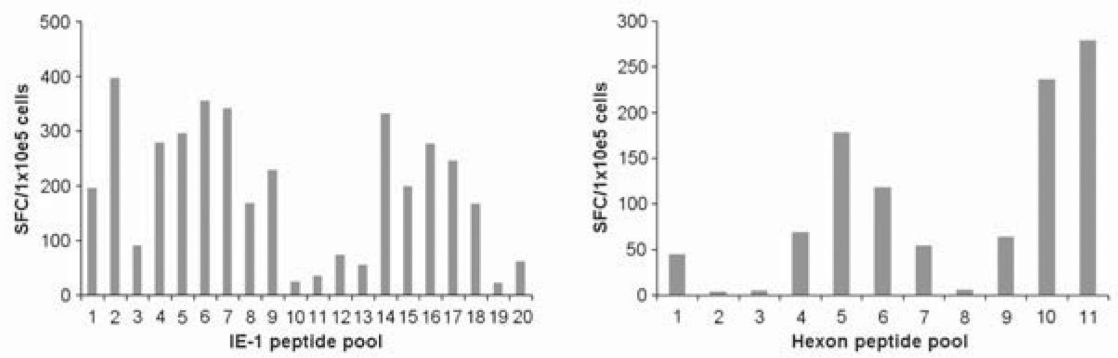

C

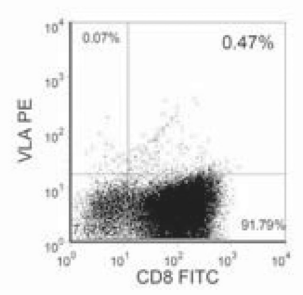

IE1

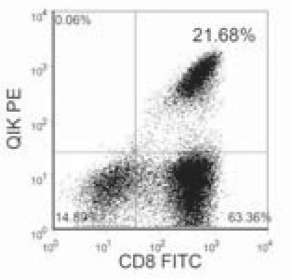

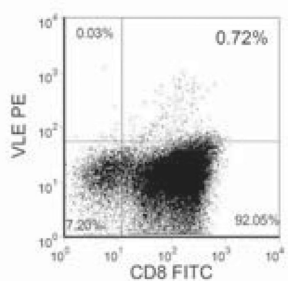

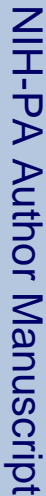

Figure 3.
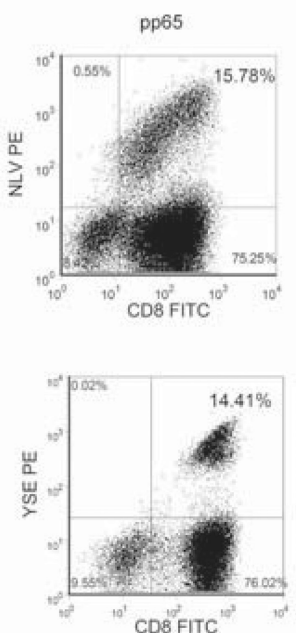

CMVpos 6

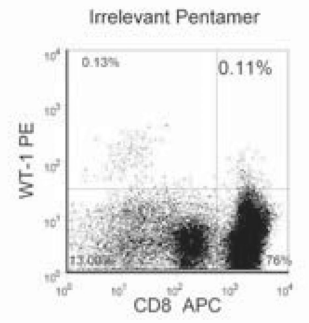

CMVpos 13

Epitope mapping of CMV-IE-1, CMV-pp65 and Ad-hexon. (a, b) Ad5f35-IE-1-I-pp65 T cells were screened by ELISPOT against 11 pools of hexon peptides, 21 pools of pp65 peptides and 20 pools of IE-1 peptides (all of which contain 20-mer peptides overlapping by 15 amino acids) to identify which peptides for each antigen were recognized by each T-cell line. Two representative donors are shown. Results are expressed as the number of SFC/100 000 cells. (c) Where available, identified epitopes were confirmed by pentamer analysis for HLA-A1-, HLA-A2-, HLA-A24-, HLA-B7- and HLA-B8-restricted epitopes. Indicated is the percentage of pentamer-positive cells within the $\mathrm{CD} 8^{+}$population. Two representative donors are shown. 

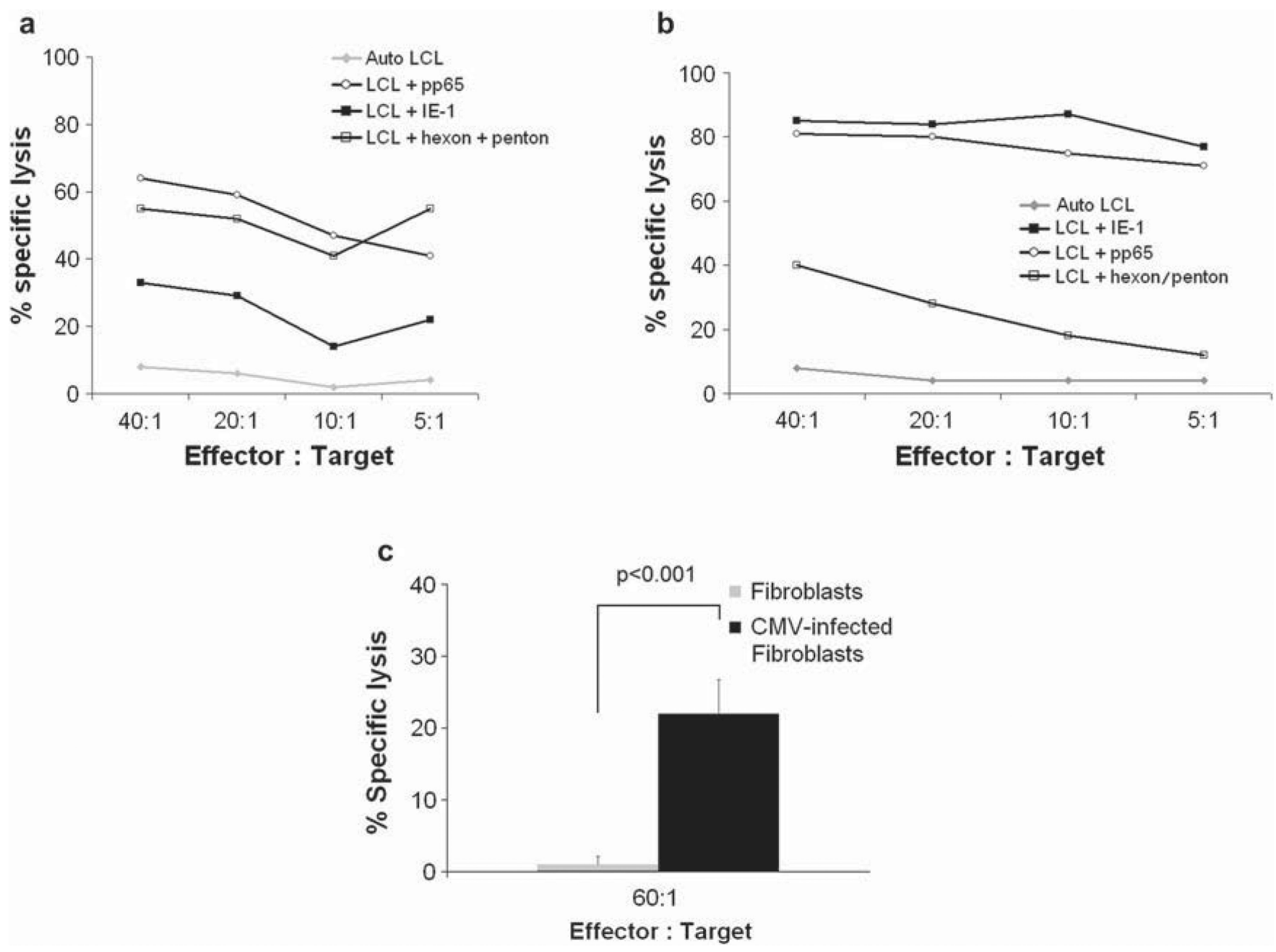

Figure 4.

Cytolytic function of Ad5f35-IE-1-I-pp65 T cells. (a, b) ${ }^{51} \mathrm{Cr}$ release after $4 \mathrm{~h}$ of coincubation of autologous EBV LCL with CMV-IE-1, CMV-pp65 and Ad-hexon/penton pepmix or EBV LCL alone with Ad5f35-IE-1-I-pp65 T cells. The data are the percentage of lysis at E:T ratios of 40:1, 20:1, 10:1, and 5:1. (c) ${ }^{51} \mathrm{Cr}$ release after $6 \mathrm{~h}$ of incubating Ad5f35-IE-I-I-pp65 T cells with allogeneic HLA-A2 + CMV AD169-infected or uninfected fibroblasts. Error bars indicate the standard deviation of the triplicates. 


\section{Table I}

Specificity of CTL lines for IE-1, pp65 and hexon. Three-letter abbreviations represent known epitopes while numbers represent individual peptide pools.

\begin{tabular}{lllll}
\hline ID & HLA & pp65 epitope & IE-1 epitope & Hexon epitope \\
\hline CMVpos 3 & A1, 24; B8, 58 & YSE & QIK & Pool 6 \\
CMVpos 5 & A2, 3; B35, 46 & Pools 1,2,9,12,15,16 & Not Identified & Pools 1, 4,7-10 \\
CMVpos 6 & A2, 24; B8, 65 & NLV & VLE & Pools 1,3,4,7,11 \\
CMVpos 7 & A2, 33; B15, 44 & NLV & VLE & Pools 1,4,7-11 \\
CMVpos 8 & A2, 29; B7, 44 & TPR, RPH, NLV & VLA & Pool 10 \\
CMVpos 9 & A2, 3; B7, 44 & TPR, RPH, NLV & VLA, KAR & Pools 4,6,7,8,11 \\
CMVpos 10 & A11, 23; B18, 44 & Pools 1-11,13,15,17,19-21 & Pools 1-18,20 & Not identified \\
CMVpos 11 & A1, 11; B8, 49 & YSE & Pools 1,2,5,7,19,20 & Pools 1,6,11 \\
CMVpos 13 & A1, 32; B8, 51 & YSE & QIK & Pools 7,11 \\
\hline
\end{tabular}

A response is defined as positive when the pentamer population is distinct and above negative controls (isotype). A peptide epitope or pool is labeled positive when the spots are 25 or more above background, and 10 or more spots above background in the case of hexon. 


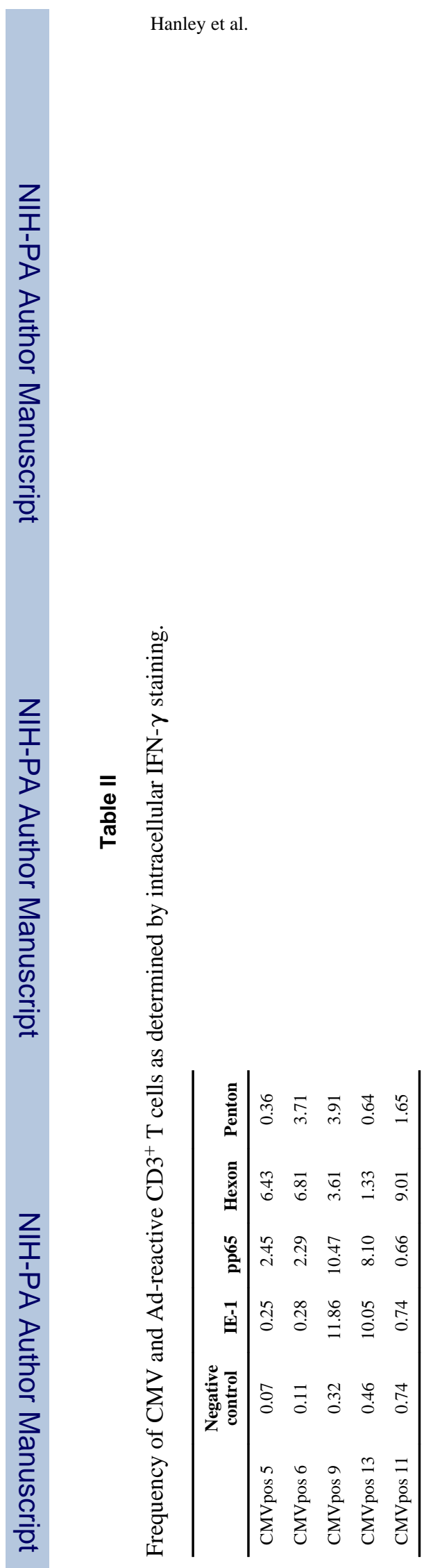

Cytotherapy. Author manuscript; available in PMC 2013 June 25. 


\section{Table III}

Cytotoxicity of T cells cultured with autologous LCL alone or pulsed with CMV-IE-1, CMV-pp65 or Adhexon/penton peptides. The table shows results at an effector:target of 40:1 (\% specific lysis).

\begin{tabular}{lrccc}
\hline ID & LCL alone & LCL + IE-1 & LCL + pp65 & LCL + hexon/penton \\
\hline CMVpos 3 & 18 & 56 & 64 & 64 \\
CMVpos 5 & 0 & 12 & 16 & 35 \\
CMVpos 6 & 8 & 33 & 64 & 55 \\
CMVpos 7 & 17 & 28 & 58 & 52 \\
CMVpos 8 & 8 & 63 & 74 & 13 \\
CMVpos 9 & 8 & 85 & 81 & 40 \\
CMVpos 10 & 27 & 50 & 69 & 61 \\
CMVpos 11 & 41 & 58 & 50 & 93 \\
CMVpos 13 & 44 & 83 & 80 & 52 \\
\hline
\end{tabular}

CMVpos 3 is at an E:T ratio of 20:1 because of an inadequate number of targets available. 